\title{
Educação do campo: perspectiva concreta ou promessa frustrada de política pública?
}

\author{
Gislaine Cristina Pavini ${ }^{1}$ \\ Maria Lucia Ribeiro ${ }^{2}$ \\ Dulce Consuelo Andreatta Whitaker ${ }^{3}$ \\ Vera Lúcia Silveira Botta Ferrante ${ }^{4}$
}

\begin{abstract}
RESUMo: O presente artigo tem como objetivo resumir a famosa polêmica entre conteudismo universalizante e Educação do/no Campo, organizando o debate teórico através do qual se justifica não só a especificidade dessa nova técnica de ensino aprendizagem, refletindo sobre a importância da qualidade para a Educação do Campo no Brasil e os objetivos e a relevância das Políticas Públicas para o campo. Como metodologia, realizamos um levantamento bibliográfico, sobre os autores que estudam as Escolas do Campo (EC) como um instrumento de valorização do homem do campo no processo de ensino aprendizagem. Analisamos e discutimos também as políticas públicas implantadas para o campo como: Pronera; Escola Ativa; Projovem Campo; Programa Dinheiro Direto na Escola do Campo; Programa de Construção de Escolas no Campo e Procampo. Verificamos que embora sejam várias as políticas públicas estabelecidas para o campo nem todas as EC conseguem participar destes programas, por conta de demasiada burocracia exigida, ou por já estarem inseridas em políticas urbanas, adaptadas para o campo.
\end{abstract}

Palavras-chave: Educação do Campo. Assentamentos Rurais. Escola do Campo.

\section{RURAL EDUCATION: CONCRETE PERSPECTIVE OR FRUSTRATED PROMISE OF PUBLIC POLICY?}

Aвstract: This article aims to summarize the famous controversy between universalizing content and Education in/of Field, organizing the theoretical debate through which the specificity of this new teachinglearning technique is justified, reflecting on the importance of quality for the Education in/of Field in Brazil and the objectives and relevance of public policies for the field. As a methodology, we carried out a bibliographical survey, about the authors who study the Schools of the Field (SF) as an instrument of valorization of the country man in the teaching-learning process. We also analyzed and discussed public policies implemented for the field, such as: Pronera; Active School; Projovem Campo; Direct Money Program at Escola do Campo; Program for the Construction of Schools in the Countryside and Procampo. We found that although there are several public policies established for the countryside, not all SF are able to participate in these programs, due to too much bureaucracy required, or because they are already inserted in urban policies, adapted to the countryside.

KEYwORDs: Rural Education. Rural Settlements. Country school.

\footnotetext{
Doutora em Desenvolvimento Territorial e Meio Ambiente, Universidade de Araraquara - UNIARA. E-mail: gipavini@ gmail.com

${ }^{2}$ Docente do Programa de Pós-Graduação em Desenvolvimento Territorial e Meio Ambiente (Mestrado e Doutorado). E-mail: ml.ribeiro@unesp.br

${ }^{3}$ Docente do Programa de Pós-Graduação em Desenvolvimento Territorial e Meio Ambiente (Mestrado e Doutorado).

${ }^{4}$ Coordenadora e Docente do Programa de Pós-Graduação em Desenvolvimento Territorial e Meio Ambiente (Mestrado e Doutorado).E-mail: vbotta@techs.com.br
} 


\section{INTRODUÇÃo}

A partir das primeiras décadas do século XXI no Brasil, a preocupação com a EC gestou, não só uma nova forma de pensar educação em áreas rurais, como um elenco de políticas públicas dirigidas a resgatar os moradores do campo das injustiças e desigualdades que bloqueavam o acesso à educação para a grande maioria. Sabemos que as conquistas derivadas dessas políticas públicas, mal chegaram a se concretizar e talvez, já estejam ameaçadas. Face a isso realizamos uma reflexão teórica valorizadora da EC, com a qual vamos iluminar a exposição das políticas públicas e seus objetivos.

\section{A) EduCAÇÃo do/NO CAMPO E SUAS VERTENTES}

A necessidade de uma educação escolar de qualidade para as áreas rurais é consenso em qualquer debate sobre educação no Brasil.

Foi-se o tempo em que se pensava a escola rural, ora para fixar o homem ao campo como queria o ruralismo pedagógico dos anos 1930 no país ainda agrário, ora para transformar camponeses em operários para o ilusório desenvolvimentalismo dos militares no poder do "Brasil Potência" por eles anunciados.

No Brasil em transição do século XX para o século XXI, passou-se a exigir a escola nas áreas rurais como direito fundamental dos moradores do campo e surgiu um novo conceito de Educação que brotou dos movimentos sociais de luta pela terra; a Educação do Campo como uma educação específica em consonância com a reforma agrária o que pode ser sintetizado em brilhante trecho do pensamento de Caldart (2003), tal como segue.

O processo da luta pela terra é que aos poucos foi mostrando que uma coisa tem a ver com a outra. Especialmente quando começaram a se multiplicar os desafios dos assentamentos, ficou mais fácil de perceber que a escola poderia ajudar nisso, desde que ela fosse diferente daquela de triste lembrança para muitas famílias. Hoje já parece mais claro que uma escola não move um assentamento, mas um assentamento também não se move sem a escola, porque ele somente se move, no sentido de que vai sendo construído como um lugar de novas relações sociais, de uma vida mais digna, se todas as suas partes ou dimensões se moverem junto. E a escola, à medida que se ocupa e ocupa grande parte do tempo de vida especialmente da infância Sem Terra, se não se move junto, é de fato um freio no processo mais amplo (CALDART, 2003, pag. 64).

O discurso expressivo de Caldart pode ser aplicado a qualquer área rural: comunidades amazônicas, de pescadores ou quilombolas, bairros rurais etc. 
Mas nada é tão idílico. Os teóricos se desentendem! Para aqueles que, como Caldart se filiam ao pensamento de Paulo Freire, a escola do/no campo não pode mais ser a velha escola rural, precária e desligada das especificidades das populações contempladas. Embora conscientes de que o capitalismo unificou o rural e o urbano, articulando-os para acelerar sua acumulação, esses pensadores percebem resistências e alternativas e captam as especificidades de cada situação cultural, o que exige que os conhecimentos curriculares tenham como ponto de partida a riqueza das práticas culturais e das lutas dos oprimidos (FREIRE,1977). Assim, os conhecimentos da educação hegemônica (leia-se capitalista) serão apreendidos e aprendidosem contraponto com os saberes das variaçõesculturaisdecada situação.

Mas há uma segunda linha entre aqueles que também se preocupam com a escolarização das áreas rurais. São autores que argumentam com o que consideram a "universalização" do pensamento capitalista, reivindicando uma não diferenciação da escolarização nas áreas rurais. Ou seja, negam a necessidade de uma diferenciação específica para espaços diferenciados porque consideram que o capitalismo como força dominante estaria exigindo uma socialização indiferenciada no processo escolar, em a qual correríamos o risco de apostar no retrocesso e no atraso (VALENTE, 2008).

Neste modo de pensar, que vai contra a Educação do/no campo, acredita-se que só assim o homem do campo pode se armar até para a luta contra o capital e se integrar à totalidade histórica, já que os conteúdos da escola dita urbana fariam parte de algo universal (a cultura) o que obviamente não existe, conforme estudos antropológicos em avanço por todo o planeta.

Assim, para os defensores da Educação dolno campo que concordam com Caldart, os conteúdos curriculares da escola hegemônica, urbanocêntrica, sociocêntrica e etnocêntrica (WHITAKER, 2008) nada tem de universal, apenas se constituem em um arbitrário cultural dominante (BOURDIEU; PASSERON,1975) através de cuja aplicação são excluídos da escola, aqueles cujos esquema de assimilação não são condizentes com tais conteúdos. Nessa direção, vejamos Lopes (2006, pag. 86).

Um dos componentes do "fracasso escolar" está na falta de interação entre os programas escolares e as características culturais dos alunos provenientes dessas populações migratórias. As demandas que se colocam hoje para as reformas educacionais enfatizam a necessidade de se estabelecer pontes mais efetivas entre os ambientes culturais dos alunos e os conteúdos formais escolares [...] precisam dialogarcomaforma comqueaescolaridadeorganizou os modos de inserção do indivíduo no conhecimento. Sem esse diálogo não existe alento para a afirmação de uma sociedade forte (LOPES, 2006, p.86). 
Em síntese: nas duas linhas desse debate há a preocupação com a aprendizagem dos conteúdos escolares e com a luta dos explorados. Mas para Caldart, Molina, Whitaker, e tantos outros, há que corrigir o caráter urbanocêntrico, sociocêntrico e racista dos currículos, tomando como ponto de partida a riqueza das práticas culturais do campo e a crítica à exploração e desvalia de que são vítimas seus moradores.

Assim, em uma aula de matemática sobre frações - essa coisa abstrata - será muitíssimo fácil para qualquer criança do campo entender tão enigmáticos conceitos se os exemplos foram baseados nos produtos da horta de seus pais ou dos queijos e doces que a mãe prepara.

E nas aulas de português, a criança escreverá rapidamente "luva" ou "facão" se os pais forem cortadores de cana e o plano de aula a partir da luva rústica que protege a mão dos cortadores na amarga tarefa do corte manual. E vai escrever qualquer palavra mais difícil - como exploração por exemplo - se puder compreender a desvalia em que vivem seus pais; ou solidariedade, se puder falar dentro da sala de aula sobre as práticas cooperativas características das áreas rurais, como por exemplo, o mutirão e as folias de reis.

Nessa linha de pensamento não se nega a importância dos conteúdos dominantes: a norma hegemônica da língua, ou seja ler bem e escrever corretamente, os usos da matemática nas diferentes profissões, conhecimentos básicos de História, Geografia e o funcionamento das instituições sociais, etc, além do valor da ciência nas sociedades ocidentais. Enfim, essa criança ou adolescente precisa desses conteúdos para uma vida melhor dentro da sociedade de classes característica do sistema capitalista. Mas só haverá a verdadeira aprendizagem destes conteúdos necessários, se a educação integrá-los às práticas e ao saber dos grupos aos quais pertencem esses alunos. Ou seja, para uma aprendizagem eficiente na zona rural, os professores precisam também aprender com seus alunos (FREIRE, 1977).

Já para os que acreditam que os conteúdos da escolaridade podem ser simplesmente expostos aos alunos, capazes de dar a ele um valor imediato, não há necessidade de fazer pontes entre os currículos oficiais e os ambientes culturais dos alunos. Basta que o professor seja bem preparado, honesto e esforçado, e acredite que o conhecimento que está ministrando é universal, ou que é o único historicamente construído, ou elaborado, com a desvalorização de todas as outras formas de saber. E então, os alunos aprenderão graças à competência do mestre.

Quando Paulo Freire estabeleceu o conceito de Educação Bancária estava observando exatamente esse tipo de professor: aquele que sabe e deposita seu "saber" em recipientes vazios - o aluno que nada sabe (FREIRE, 1977). 
Os pais têm razão quando afirmam que seus filhos não precisam ir à escola para aprender o que já sabem, já que, é óbvio a escola não detém os saberes do aluno. Mas em projetos de Educação do/no Campo, corretamente elaborados, a criança vai à escola, também para ensinar o que aprende com seus pais nos seus grupos específicos para que possa haver a relação dialógico do ensino aprendizagem com o professor (FREIRE, 1974). Mas se a escola tentar ensinar aos alunos aquilo que eles já sabem, então essa não é a Educação do Campo. É simplesmente ruralismo pedagógico (WHITAKER, 2008).

Aqui, pergunta-se: como ter uma educação de qualidade nas áreas rurais se a escola urbanocêntrica tem como ponto de partida, sempre, o capital cultural que apenas uma pequena camada tem condições de acumular? Esse é um dos motivos das escolas particulares terem maior eficiência.

Poder-se-ia pensar em uma pedagogia que valorize a sabedoria e a beleza da cultura acumulada dos que trabalham na terra e, não somente, tornar uma aprendizagem com conteúdo específico para o capitalismo e, sim, que seja uma Educação do/no Campo significativa para que não sejam abandonados daqueles que optam pela vida do campo: "Aqueles que optam pela vida do campo sabem que estão optando por uma grande desvalia, face ao abandono que o Estado lhes reserva e aos preconceitos que vão enfrentar" (WHITAKER, 2008).

Põe-se, portanto, como perspectiva de transformação da educação tradicional, a qual se pauta, segundo Whitaker (1992), por vieses urbanocêntricos, voltados para os conteúdos que informam e são informados no processo de urbanização, por privilegiar a cultura relativa ao mundo ocidental, a chamada racionalidade do capitalismo (FENG; FERRANTE, 2008, p.196).

Esta reflexão teórica é importante para que se possa analisar as políticas públicas para a Educação do Campo nos últimos anos já que essas políticas se justificam exatamente pelas colocações teóricas dos que defendem a educação dialógica como direito humano e justiça social para os moradores das inúmeras e diferenciadas áreas rurais deste país.

\section{B) Avaliação das Políticas Públicas}

Ao longo da trajetória do contexto histórico do campo e suas políticas públicas, a articulação, entre as políticas públicas para a EC, é um dos principais desafios enfrentados para sua consolidação. Ao discutir e refletir sobre Políticas Públicas e suas implementações para o campo, é necessário compreender melhor esse arcabouço educacional em que "o destinatário da educação rural é a população agrícola constituída por todas aquelas pessoas para as quais a agricultura representa o principal meio de sustento" (PETTY; TOMBIM; VERA, 1981, p. 33). 
A efetividade de políticas públicas para a Educação do Campo, foi discutida por Pavini e Ribeiro (2017) e teve como objetivo refletir sobre as políticas públicas e suas implementações para EC o que contribuiu significativamente para enriquecer o embasamento teórico sobre as políticas públicas para o campo. Neste evento, foi realizada uma discussão interdisciplinar sobre a temática que, com a participação de profissionais interessados em diferentes áreas como educação, saúde, assistência social, segurança alimentar, reafirmaram assim, a importância da efetivação das políticas públicas para a EC.

Nesta perspectiva é importante garantir os direitos sociais a todos os camponeses, especialmente, os direitos à educação, mas para isso, é importante uma política diferenciada, definida com a presença e participação de todos os envolvidos. Para que isso fosse possível, foi realizado análise documental de legislações de políticas públicas para a EC, que compreendem desde creche até graduação, ofertadas por responsabilidade compartilhada entre União, Estados e Municípios como: Programa Nacional de Educação na Reforma Agrária (Pronera); Escola Ativa, que concede bolsas para educadores de instituições públicas de ensino superior que trabalham na qualificação dos professores que lecionam em escolas multisseriadas; Projovem Campo, destinado a agricultores com idade entre $18 \mathrm{e}$ 29 anos, alfabetizados, mas que ainda não concluíram o ensino fundamental (em regime de alternância) e Procampo, Apoio à Formação Superior em Licenciatura em Educação no Campo que oferece graduação a professores das escolas rurais que lecionam no ensino fundamental e no médio.

As políticas públicas e suas implementações para EC precisam ser mais discutidas e colocadas em práticas pela população do campo. No Decreto 7.352 de 4 de novembro de 2010, que dispõe sobre a política de Educação do Campo, encontramos quem são os povos do campo:

As populações que residem no campo compreendem os agricultores familiares, os extrativistas, os pescadores artesanais, os ribeirinhos, os assentados e acampados da reforma agrária, os trabalhadores assalariados rurais, os quilombolas, os caiçaras, os povos da floresta, os caboclos e outros que produzam suas condições materiais de existência a partir do trabalho no meio rural (BRASIL, 2010).

A esses cidadãos, a escola deve atender respeitando princípios, entre os quais se destaca o respeito à diversidade no que tange aos aspectos sociais, culturais, ambientais, políticos, econômicos, de gênero, raça e etnia. Esse Decreto também regulamenta o Programa Nacional de Educação na Reforma Agrária - PRONERA, executado pelo Ministério do Desenvolvimento Agrário e pelo Instituto Nacional 
de Colonização e Reforma Agrária (INCRA) e define objetivos, beneficiários e atribuição da gestão ao INCRA.

O levantamento e análise das legislações referentes às Políticas Públicas, principalmente o Decreto 7.352 de 04 de novembro de 2.010, que dispõe sobre as políticas de Educação do Campo, as quais contemplam desde creche até graduação, ofertadas por responsabilidade compartilhada entre União, Estados e Municípios, aborda que:

A política de educação do campo destina-se à ampliação e qualificação da oferta de educação básica e superior às populações do campo, e será desenvolvida pela União em regime de colaboração com os Estados, o Distrito Federal e os Municípios, de acordo com as diretrizes e metas estabelecidas no Plano Nacional de Educação (BRASIL, 2010).

Este decreto atribui ao governo federal a responsabilidade de criar e implementar mecanismos que assegurem a manutenção e o desenvolvimento da educação na área rural. Para isso, busca superar a defasagem e acesso à educação, tendo como proposta a redução do analfabetismo de jovens e adultos; fomentação da educação básica na modalidade jovens e adultos (tanto na qualificação social e profissional); garantia de fornecimento de energia elétrica, água potável e saneamento básico para as escolas, promoção da inclusão digital e formação de professores que lecionam nas escolas rurais.

Para receber assistência técnica e recursos do governo federal os estados e municípios são orientados a incluírem a EC nos seus planos estaduais e municipais que devem ser construídos a partir do Plano Nacional de Educação (PNE) que estabelece as metas educacionais a serem alcançadas pelo Brasil, no período de 2011 a 2020.

As políticas públicas para o campo, permanecem e estão em constante debate para estimular a formação de professores, elevar o desempenho dos alunos e melhorar a estrutura das EC. Para atender essas demandas, são desenvolvidos programas como: Programa Nacional de Educação na Reforma Agrária (Pronera), executado pelo Ministério do Desenvolvimento Agrário e pelo Instituto Nacional de Colonização e Reforma Agrária (Incra), que define objetivos, beneficiários e atribuições da gestão ao Incra. O público alvo compreende jovens e adultos das famílias atendidas pelos projetos de assentamento do Incra e professores e educadores que atuam no programa, além das famílias cadastradas e alunos dos cursos de especialização do Incra. Ao Incra, cabe a atividade de gestão, coordenação e gerenciamento dos projetos, produção de manuais técnicos para as atividades, além de coordenar a comissão pedagógica nacional.

A formação docente deste programa acontece em três frentes: a primeira 
com a formação de educadores para atender as necessidades de alfabetização e escolarização de adultos, a segunda na formação em nível superior para atuação na série iniciais como por exemplo, os cursos Pedagogia da terra e Pedagogia do Campo e a terceira que respeito à formação docente para atuar nos anos finais do Ensino Fundamental e Médio, todos por meio dos cursos de licenciatura. A proposta de formação do Pronera busca o questionar constante, propondo uma metodologia voltada em experiências vivenciadas e agregadas a elementos do cotidiano na formação docente.

Outro programa que também prioriza a formação de docentes do campo, é o Programa de Apoio à Formação Superior em Licenciatura em Educação no Campo (Procampo) que oferece graduação aos professores das escolas rurais que lecionam nos anos finais do ensino fundamental e no médio. Atualmente, 31 instituições públicas de ensino superior oferecem licenciatura em educação no campo. Segundo o Censo Escolar 2009, trabalham em escolas rurais 338 mil educadores. Destes, somente 138 mil têm nível superior. O desafio da União, estados e municípios foi oferecer graduação a 196 mil professores que lecionam no campo apenas com formação de nível médio. O Procampo por ser um programa de apoio a formação superior em licenciatura em E. C., é considerado uma nova modalidade de graduação nas universidades públicas brasileiras. Sua licenciatura objetiva formar e habilitar profissionais para atuar nos anos iniciais do ensino fundamental e médio. E tem como objeto de estudo e de prática as escolas de Educação Básica do Campo que buscam articular três dimensões no perfil de formação: preparar para habilitação da docência por área de conhecimento para a gestão dos processos educativos escolares e para a gestão de processos educativos comunitários. A organização curricular das disciplinas do curso são ofertadas de forma diferenciada, na universidade quando os alunos estão estudando, as aulas ocorrem em intervalos mensais no formato integral (manhã, tarde e noite) e também são oferecidas disciplinas no período de férias escolares de janeiro e julho. Já a aprendizagem entre essas aulas, ocorre na sua comunidade local no qual os alunos, futuros professores, realizam atividades de estudo e pesquisas. Essa é uma aprendizagem intrínseca entre educação e realidade específica das populações do Campo.

Outro projeto importante, é o Projovem, um programa do governo federal destinado a agricultores com idade entre 18 e 29 anos alfabetizados, mas que não tenham concluído ainda o ensino fundamental. Por algum motivo, esses alunos foram excluídos da escolarização, e o Projovem visa reintegrá-los ao processo educacional, elevar sua escolaridade e promover sua formação social e qualificação profissional. Tem como objetivo certificar os alunos na conclusão do ensino fundamental com qualificação em agricultura familiar por meio de um 
curso com duração de 2 anos em regime de alternância, intercalando atividades na escola com atividades realizadas no contexto da família e da comunidade. Este programa complementa a remuneração do quadro efetivo de professores da rede de ensino com pagamento de profissionais contratados para atuarem na formação continuada destes educadores. Também beneficia os estudantes/agricultores participantes com uma bolsa remunerada, mas para isso têm que cumprir $75 \%$ da frequência do curso, como já mencionado. Pode também ter um formato particular sob a responsabilidade de cada estado seguindo as características da agricultura local.

O Programa Escola Ativa concede bolsas de estudo e de pesquisa para educadores de instituições públicas de ensino superior, supervisores das secretarias estaduais de educação e professores. Esses bolsistas trabalham na qualificação dos professores que lecionam em escolas multisseriadas. Das 83 mil escolas rurais do país, 39 mil trabalham com essas classes e, abarcam 1,3 milhão de estudantes do ensino fundamental (INEP, 2009). Este programa teve como marco no Brasil um convênio com Banco Mundial com o objetivo de melhorar o rendimento de alunos de classes multisseriadas rurais. Tem como foco a formação de professores e a melhoria da infraestrutura das escolas propondo amplas mudanças na organização do trabalho docente. É considerado o único programa voltado especificamente ao apoio as escolas rurais com classes multisseriadas que atende alunos do $1^{\circ}$ ao $5^{\circ}$ ano do ensino fundamental da rede pública. Seu histórico é marcado pela coexistência dos movimentos sociais que defendiam novos princípios para a educação do meio rural alinhado com os próprios interesses de um novo conceito de Educação do Campo. Surgiu, pois a maioria dos municípios brasileiros possuem escolas em áreas rurais e em muitas dessas escolas, o único professor da sala de aula, ensina vários alunos de idades e séries diferentes, nas conhecidas classes multisseriadas. O programa busca principalmente, capacitar esses professores que ministram as aulas nessas classes multisseriadas para auxiliar e tentar beneficiar a aprendizagem dos alunos que muitas vezes estão em defasagem escolar.

As escolas rurais multisseriadas estão incluídas também no Programa Dinheiro Direto na Escola do Campo (PDDE Campo) que repassa recursos em espécie para ações prioritárias de infraestrutura e aquisições de materiais. O PDDE tem por finalidade prestar assistência financeira às escolas, a fim de contribuir com a manutenção e a melhoria da infraestrutura física e pedagógica para que se possa elevar o desempenho escolar dos alunos. As principais estratégias estão: implantar nas escolas recursos pedagógicos que estimulem a construção do conhecimento do aluno e a capacitação de professores. O recurso financeiro para este programa é liberado em favor das escolas de Educação Básica para a contratação de mão de 
obra para a realização de reparos ou pequenas ampliações, além da cobertura de outras despesas que favoreçam a manutenção, conservação e melhoria de suas instalações física, além da aquisição de mobiliário escolar e na concretização de outras ações que concorrem para elevação do desempenho escolar. Este recurso pode variar de acordo com o número de matrículas, ou seja, com quanto maior o número de matrículas maior a verba recebida pela escola.

Já o Programa de Construção de Escolas no Campo desenvolvido pelo governo federal oferece aos estados e municípios projetos arquitetônicos. Ele oferece aos estados e municípios apoio financeiro para construção de escolas públicas no campo e em áreas de assentamentos de reforma agrária. Ele surgiu da necessidade de promover ações voltadas para a melhoria da qualidade do ensino e da infraestrutura das Escolas do Campo, visando superar o quadro de precariedade que muitas vezes as caracteriza e visa a propiciar um ambiente adequado às atividades de aprendizagem escolar valorizando sempre as especificidades do ambiente rural e da diversidade cultural e social em que a comunidade está inserida. Ao priorizar condições de construção, acesso e utilização de todos os ambientes dentro da escola, como por exemplo, salas de aula, bibliotecas, auditórios, ginásios esportivos, laboratórios, banheiros e mobilidade a pessoas portadoras de deficiência física, contribui para a melhoria da aprendizagem dos alunos.

Portanto, as políticas públicas voltadas para o campo apresentam um amplo arcabouço educacional, porém, não são sistematicamente colocadas em prática, pois muitas vezes o que presenciamos, são políticas da cidade adaptadas ao campo e, mesmo que remodeladas, nem sempre, contemplam suas necessidades reais. Importante ainda ressaltar que essas implementações, para EC, mesmo tendo diversos programas não são amplamente divulgadas ou conhecidas pelos seus atores.

\section{Conclusão}

Nossa intenção, neste texto, desenvolvido a partir das pesquisas sobre Políticas Públicas para EC foi levantar o amplo espectro de ações afirmativas na direção de alunos e seus professores em escolas rurais - ações afirmativas essas que visavam corrigir a injustiça secular, mais do que secular, sofrida pelos moradores do campo no que se refere a um direito básico nunca antes levado em conta por inúmeros governos que se sucederam neste país.

Pudemos constatar que as políticas públicas para o campo, permanecem e estão em constante debate para estimular a formação de professores, implementar nas escolas recursos pedagógicos que potencializem a construção do conhecimento do aluno, incentivar a capacitação de professores, inserir os alunos que foram 
excluídos da escolarização na idade certa, melhorar a estrutura das Escolas do Campo e elevar o desempenho discente.

Talvez tudo isso esteja ameaçado de desvanecimento. Daí a relevância de se colocar o foco teórico inicial desse artigo, re-afirmando a especificidade da educação rural. O embasamento teórico, no caso, é a melhor defesa que temos para garantir as conquistas expressas por essas políticas públicas, antes que sejam suprimidas pelo governo.

Verificamos que há um número razoável de políticas públicas para o campo em nosso país e que uma EC pode fazer parte de vários desses programas. Porém, nem sempre as EC conseguem participar, de pelo menos um desses programas, porque a burocracia exigida, como padrões educacionais já estabelecidos e anteriormente comprovados, nem sempre são estabelecidos pelos gestores dessas escolas, ou também porque as políticas públicas nas quais as escolas já estão inseridas, são políticas da cidade adaptadas para o campo.

Esperamos que este artigo possa servir de base para outros estudos de valorização da Educação do/no Campo e do homem do campo, sua escolarização e a efetividade das políticas públicas para o campo em seus objetivos.

\section{REFERÊNCIAS}

BOURDIEU, P. ; PASSERON, J. C. A Reprodução. Rio de Janeiro: Livraria Francisco Alves, 1975.

BRASIL. Governo Federal. Pronera. Decreto n.7.352, de 04 de Novembro de 2.010. Brasília: 2010.

CALDART, R. S.A escola do campo em movimento. Currículo sem fronteiras, EUA, v.3, n.1, jan/jun 2003, p.60-81.

FENG, L. Y;; FERRANTE, V. L. S. Projeto educação do campo: estratégias e alternativas no campo pedagógico. Retratos de Assentamentos, Araraquara, v. 1, n. 11, p. 195-224, 2008.

FREIRE, P. Pedagogia do Oprimido. São Paulo: Paz e Terra, 1977.

LOPES, W. de J. F. Profissionalidade Docente na Educação do Campo. 2013. 253 f. Tese (Doutorado em Educação) - Universidade Federal de São Carlos. São Carlos. 2013. 
MOLINA, M. C. Educação do campo e pesquisa: questões para reflexão. Brasil. Ministério do Desenvolvimento Agrário. - Brasília: ministério do desenvolvimento agrário, 2006.

PAVINI, G. C.; RIBEIRO, M. L. Efetividade de políticas públicas para a educação do campo. In I Seminário Políticas Públicas e Desenvolvimento Territorial, SEPPU, UNIARA, Araraquara/SP, 2017. Anais do I Seminário Políticas Públicas e Desenvolvimento Territorial, 2017.

PETTY, M.; TOMBIM, A.; VERA, R. Uma alternativa de educação rural. In: Werthein, J.; Bordenave, J. D. (org.). Educação rural no Terceiro Mundo. Rio de Janeiro: Paz e Terra, 1981. p. 31-64.

VALENTE, A. L. E. F. A Educação no campo e a sua realidade: a esquizofrenia teórica em xeque. Retratos de Assentamentos. Araraquara, v.1, n. 11, p. 261-281, 2008.

WHITAKER, D. C. A. Educação Rural: da razão dualista, à razão dialética. Retratos de Assentamentos, Araraquara, v. 1, n. 11, p. 295-304, 2008. 